\title{
Cathepsin D mediates cytochrome $c$ release and caspase activation in human fibroblast apoptosis induced by staurosporine
}

\author{
A-C Johansson ${ }^{*, 1}$, H Steen ${ }^{1}$, K Öllinger ${ }^{1}$ and K Roberg ${ }^{1,2}$ \\ 1 Division of Pathology II, Faculty of Health Sciences, Linköping University, \\ S-58185 Linköping, Sweden \\ 2 Division of Oto-rhino-laryngology, Faculty of Health Sciences, Linköping \\ University, S-58185 Linköping, Sweden \\ * Corresponding author: A-C Johansson. Tel: + 46-13-221500; \\ Fax: + 46-13-221529; E-mail: lotta.johansson@ inr.liu.se
}

Received 23.9.02; revised 29.3.03; accepted 19.5.03

Edited by $\mathrm{G}$. Salvesen

\begin{abstract}
There is increasing evidence that proteases other than caspases, for example, the lysosomal cathepsins B, D and L, are involved in apoptotic cell death. In the present study, we present data that suggest a role for cathepsin $D$ in staurosporine-induced apoptosis in human foreskin fibroblasts. Cathepsin $D$ and cytochrome $c$ were detected partially released to the cytosol after exposure to $0.1 \mu \mathrm{M}$ staurosporine for $1 \mathrm{~h}$. After $4 \mathrm{~h}$, activation of caspase- 9 and -3 was initiated and later caspase-8 activation and a decrease in full-length Bid were detected. Pretreatment of cells with the cathepsin $D$ inhibitor, pepstatin A, prevented cytochrome $c$ release and caspase activation, and delayed cell death. These results imply that cytosolic cathepsin $D$ is a key mediator in staurosporine-induced apoptosis. Analysis of the relative sequence of apoptotic events indicates that, in this cell type, cathepsin $D$ acts upstream of cytochrome $c$ release and caspase activation.
\end{abstract}

Cell Death and Differentiation (2003) 10, 1253-1259. doi:10.1038/ sj.cdd. 4401290

Keywords: apoptosis; caspases; cathepsin D; cytochrome $c$; fibroblasts; lysosomes

Abbreviations: AMC, 7-amino-4-methyl coumarin; AFC, 7amino-4-trifluoromethyl coumarin; DPPD, $N, N$-diphenyl-1,4-phenylene-diamine; GAPDH, glyceraldehyde-3-phosphate dehydrogenase; PBS, phosphate-buffered saline; TBS, Tris-buffered saline

\section{Introduction}

Apoptosis occurs through activation of a cell suicide process regulated by many different intracellular and extracellular events. It is generally accepted that caspases play an essential role in the induction and execution of apoptosis. There are two distinct pathways leading to caspase activation and ensuing apoptosis (reviewed by Cohen). ${ }^{1}$ In the death receptor pathway, activation of caspase-8 is induced by ligation of the receptors and mediated by their interaction with intracellular adapter molecules. In the mitochondrial pathway, the release of cytochrome $c$ from mitochondria is a crucial step in the activation of caspases. Once released to the cytosol, cytochrome $c$ associates with apoptosis protein-activating factor-1 (Apaf-1), forming an apoptosome complex that, in the presence of ATP or dATP, is capable of activating procaspase-9. Initiator caspases, activated through either one of these two pathways, can in turn activate caspase-3 and other effector caspases responsible for dismantling of the dying cell. Therefore, biochemical and morphological changes, including cellular shrinkage, chromatin condensation and DNA fragmentation, are almost invariably involved in both pathways.

In addition to caspases, lysosomal proteases such as cathepsins $B, D$ and $L$ have been shown to act as mediators of apoptosis in several cell types. ${ }^{2-9} \mathrm{~A}$ recent study by Stoka et al., ${ }^{10}$ in which the proapoptotic Bcl-2 family member Bid was cleaved to its active form in the presence of lysosomal extracts, suggests the possible involvement of lysosomal proteases in apoptosis. The protease responsible for this cleavage was not identified, but lysosomal cathepsins are possible candidates. The participation of the cysteine protease cathepsin $L$ in the activation of downstream caspases has been illustrated in studies performed by Katunama et al and Ishisaka et al. ${ }^{8,9}$ In these studies, caspase-3 was found to be activated by digitonin-treated lysosomal fractions. Cathepsin $L$ was suggested to cleave and activate two new lysosomal proteases, called lysoapoptases, which in turn activated caspase-3. The involvement of another lysosomal cysteine protease, cathepsin $B$, in apoptosis was suggested by Guicciardi et al. ${ }^{2}$ In TNF- $\alpha$-exposed hepatocytes, caspase8 induced lysosomal release of cathepsin $B$, which in turn mediated the release of cytochrome $c$ from mitochondria. Cathepsin B has, however, also been suggested to be a negative regulator of apoptosis. ${ }^{11,12}$ Overexpression of cathepsin B in PC12 cells lowered their sensitivity to apoptosis induced by serum deprivation, while inhibition of cathepsin B had the opposite effect.

In the case of cathepsin D, Deiss et al. ${ }^{13}$ were the first to prove that this aspartic protease is an important mediator of apoptosis. Using cathepsin D antisense RNA or the cathepsin $D$ inhibitor pepstatin $A$, they demonstrated an inhibition of apoptosis in IFN- $\gamma$ - or Fas-treated HeLa cells as well as in TNF- $\alpha$-treated U937 cells. In previous studies, we have demonstrated translocation of cathepsin $D$ from lysosomes to the cytosol in cardiomyocytes and fibroblasts exposed to oxidative stress. ${ }^{6,14}$ This translocation preceded mitochondrial cytochrome $c$ release and caspase activation, suggesting a role for cathepsin D upstream of mitochondrial events. In agreement with this theory, the cathepsin $D$ inhibitor, pepstatin A, prevented the release of cytochrome $c$, caspase activation and cell death. ${ }^{4,6,15}$ More recently, our group has 
provided compelling evidence for a proapoptotic role of cathepsin $D$ after microinjection of the enzyme directly into the cytosol of human foreskin fibroblasts. ${ }^{16}$ Cathepsin D microinjection resulted in cytochrome $c$ release from mitochondria and subsequent caspase-dependent apoptosis; events that were inhibited when pepstatin A was coinjected.

In the present study, we evaluate the importance of cathepsin $D$ in human foreskin fibroblast apoptosis induced by staurosporine, a broadspectrum protein kinase inhibitor. Our results suggest that cathepsin $D$ is a positive mediator of staurosporine-induced apoptosis, acting upstream of cytochrome $c$ release and caspase activation.

\section{Results}

\section{Inhibition of cathepsin D delays staurosporine- induced apoptosis}

Staurosporine exposure results in morphological signs of apoptosis in many cell types but the exact mechanism for the induction of apoptosis is not known. In human foreskin fibroblasts exposed to $0.1 \mu \mathrm{M}$ staurosporine for $8 \mathrm{~h}$, a majority of the cells showed typical signs of apoptosis. Cell shrinkage and pycnotic nuclei were detected using light microscopy of Giemsa-stained cells (Figures 1a, c). Chromatin condensation, nuclear fragmentation and formation of apoptotic bodies were demonstrated by electron microscopy (Figures 2a, b).
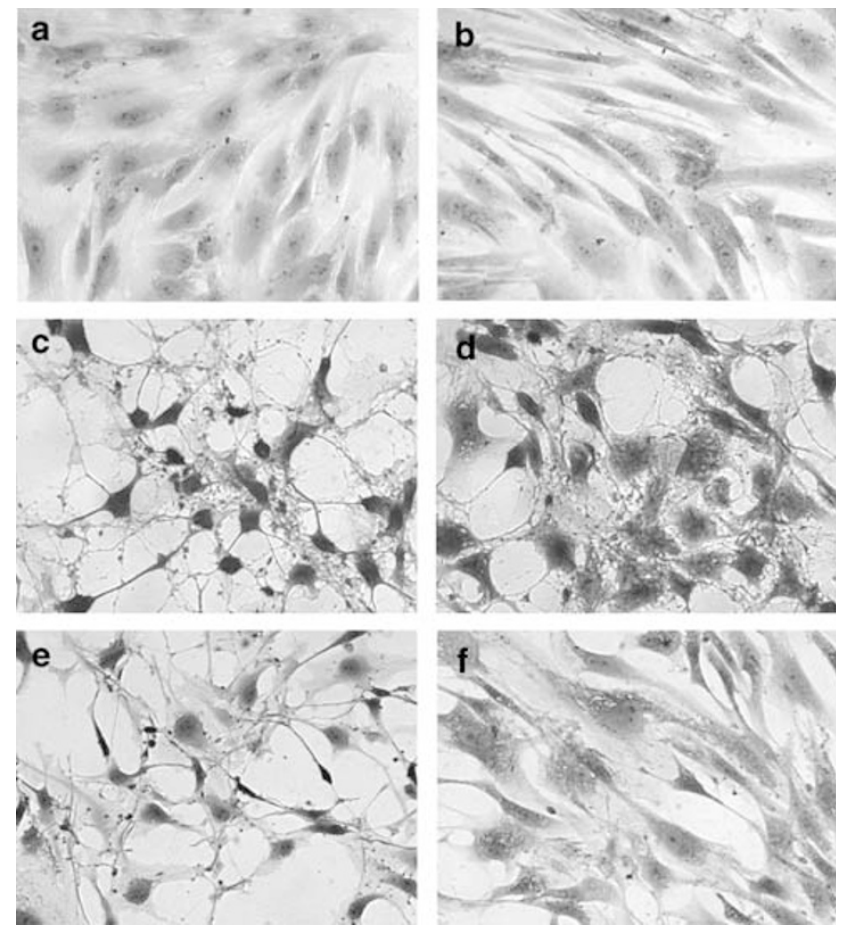

Figure 1 Inhibition of cathepsin D delays staurosporine-induced apoptosis. Morphology of human foreskin fibroblasts stained with Giemsa. (a) Control cells. (b) Control cells pretreated with pepstatin A (100 $\mu \mathrm{M}, 24 \mathrm{~h})$ (c) Cells exposed to $0.1 \mu \mathrm{M}$ staurosporine for $8 \mathrm{~h}$. (d) Cells pretreated with pepstatin $A$ and then exposed to staurosporine for $8 \mathrm{~h}$. (e) Cells exposed to $0.1 \mu \mathrm{M}$ staurosporine for $1 \mathrm{~h}$ and then incubated in culture media for another $24 \mathrm{~h}$. (f) Cells pretreated with pepstatin $A$, exposed to staurosporine for $1 \mathrm{~h}$, and then incubated in culture media for another $24 \mathrm{~h}$
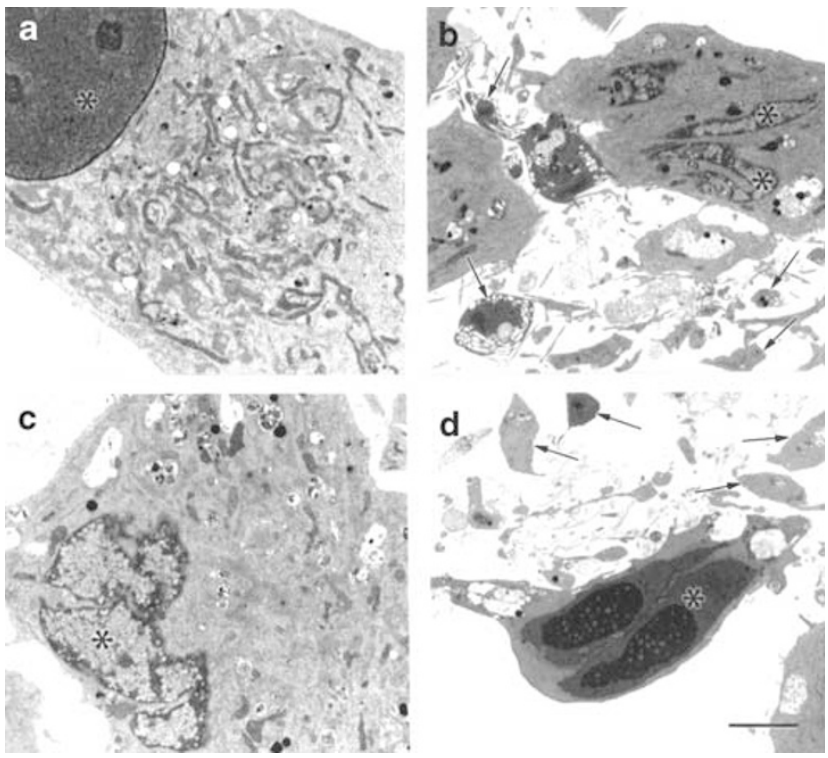

Figure 2 Inhibition of cathepsin D delays staurosporine-induced apoptosis and reduces nuclear fragmentation and condensation. Electron micrographs of human foreskin fibroblasts. (a) Control cell. (b) Cell exposed to $0.1 \mu \mathrm{M}$ staurosporine for $8 \mathrm{~h}$. (c) Cell pretreated with pepstatin $\mathrm{A}(100 \mu \mathrm{M}, 24 \mathrm{~h})$ and then exposed to staurosporine for $8 \mathrm{~h}$. (d) Cell pretreated with pepstatin $A$ and then exposed to staurosporine for $24 \mathrm{~h}$. Nuclei are marked with stars and apoptotic bodies are marked with arrows. $\mathrm{Bar}=3 \mu \mathrm{M}$

In order to investigate the role of cathepsin $D$ in staurosporine-induced apoptosis, cells were pretreated with pepstatin A, a specific inhibitor of aspartic proteases such as pepsin, renin and cathepsin $D$. The intracellular effects of pepstatin $A$ have, however, been attributed to inhibition of cathepsin D activity since cathepsin D is the major intracellular aspartic protease. ${ }^{17}$ Pretreatment of cultures with $100 \mu \mathrm{M}$ pepstatin A decreased the number of apoptotic cells after $8 \mathrm{~h}$ of exposure (Figures 1c, d). However, after extended exposure to staurosporine, pepstatin A pretreated cells could not be rescued (data not shown), indicating that inhibition of cathepsin D delays the onset of apoptosis. In addition, inhibition of cathepsin $D$ activity resulted in reduced nuclear fragmentation and condensation (Figures 2c, d). No difference in viability was seen when comparing controls and cells treated with pepstatin A only (Figures 1a, b). However, since lysosomal protease inhibition has effects on autophagocytosis, cells pretreated with pepstatin A showed an increased number of vacuoles.

We also studied the effect of a cysteine protease inhibitor, z-FA-FMK, on apoptosis. Treatment with this inhibitor, however, did not provide any protection from staurosporineinduced cell death (data not shown). These data suggest that cathepsin D, but not cysteine proteases like cathepsins $B$ and $\mathrm{L}$, mediates staurosporine-induced apoptosis in fibroblasts.

In previous studies, lysosomal destabilisation was found to be an important component of oxidative stress-induced cell death. ${ }^{14,18}$ The lipophilic antioxidant $N, N$-diphenyl-1,4-phenylene-diamine (DPPD) protected hepatocytes from the deadly effects of the redox cycling drug naphthazarin. ${ }^{18}$ Furthermore, cardiomyocytes were rescued from naphthazarin-induced cell death by pretreatment with the antioxidant 
$\alpha$-tocopherol succinate. ${ }^{14}$ In order to investigate whether the induction of apoptosis by staurosporine is mediated by oxidative events, DPPD was used. Consistent with our earlier work, treatment of fibroblasts with $2 \mu \mathrm{M}$ DPPD prevented naphthazarin-induced apoptosis; however, DPPD did not affect the viability of cells exposed to staurosporine (data not shown). These studies indicate that an oxidative mechanism is not decisive for staurosporine-induced apoptosis.

\section{Lysosomal release of cathepsin D}

Since cathepsin $D$ is released from lysosomes early during oxidative stress-induced apoptosis, ${ }^{6,14}$ we investigated the possibility of a similar translocation during apoptosis induced by staurosporine. In control fibroblasts, immunofluorescence analysis demonstrated a granular staining of cathepsin D (Figure 3a), consistent with a lysosomal distribution. Cells
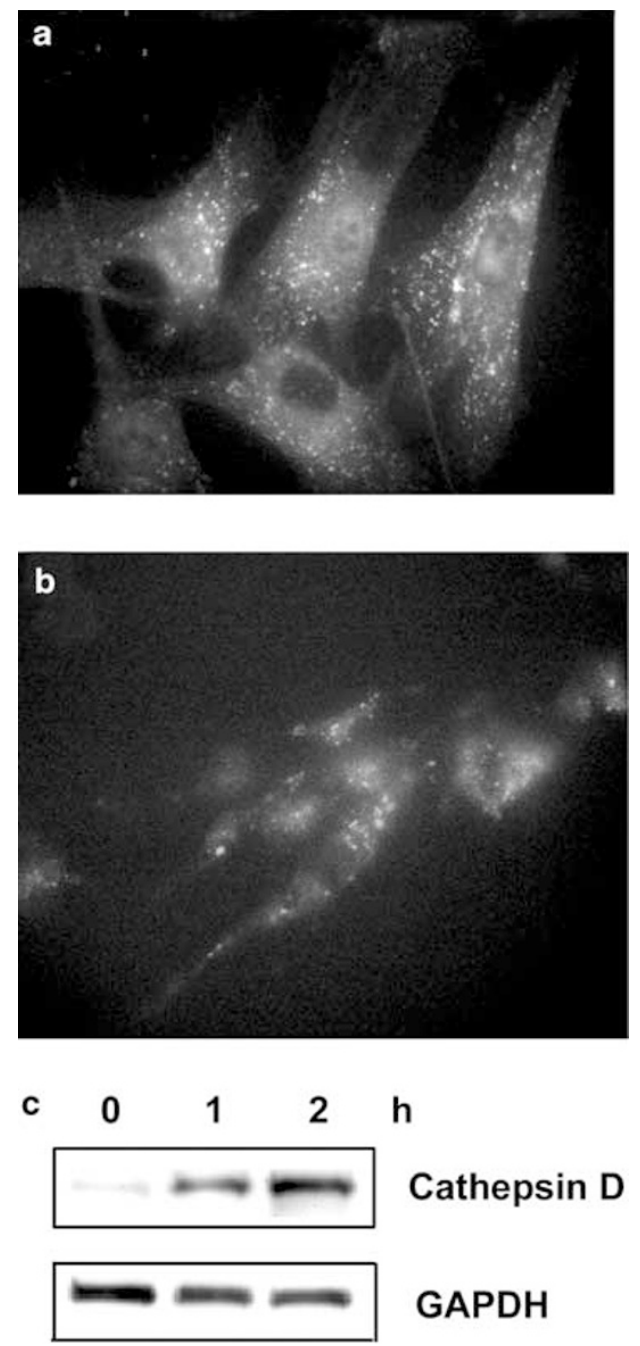

\section{GAPDH}

Figure 3 Cathepsin $D$ is released from lysosomes early in staurosporineinduced apoptosis. $(\mathbf{a}, \mathbf{b})$ Immunofluorescence detection of cathepsin $\mathrm{D}$ in human foreskin fibroblasts. (a) Control cells. (b) Cells exposed to $0.1 \mu \mathrm{M}$ staurosporine for $1 \mathrm{~h}$. (c) Western blotting of cathepsin $\mathrm{D}$ in cytosol extracted from cells exposed to staurosporine for indicated periods of time. GAPDH was used as loading control. One representative experiment out of three is shown exposed to staurosporine for $1 \mathrm{~h}$ exhibited a more diffuse staining of cathepsin $D$, implying translocation of the enzyme from lysosomes to the cytosol (Figure $3 b$ ). In accordance with earlier studies, ${ }^{4,5}$ treatment with pepstatin $A$ before staurosporine exposure did not affect the translocation of cathepsin D (data not shown). Lysosomal release was also studied by Western blot analysis of cytosol. Cytosol was extracted using digitonin, which, at the concentration used, premeabilises the plasma membrane but not the lysosomal membrane. Using this method, release of cathepsin $D$ after $1 \mathrm{~h}$ of staurosporine exposure was confirmed (Figure 3c).

In order to investigate the importance of the early lysosomal release of cathepsin $D$, cells were exposed to staurosporine for $60 \mathrm{~min}$, and then incubated in complete medium without staurosporine for another $24 \mathrm{~h}$. This short exposure resulted in widespread apoptotic cell death, detected after $24 \mathrm{~h}$ (Figure 1e). Treatment with pepstatin A before and after staurosporine exposure yielded high survival rates; only a few cells showed apoptotic morphology after $24 \mathrm{~h}$ (Figure 1f). The results from this part of the study suggest that there is an early lysosomal release of cathepsin $D$ that is important for propagation of the apoptotic signal.

\section{Inhibition of cathepsin D activity prevents mitochondrial release of cytochrome $c$}

Cytochrome $c$ has been shown to be released from mitochondria during staurosporine-induced apoptosis. ${ }^{19-21}$ In control fibroblasts, a typical mitochondrial pattern was obtained with immunofluorescence analysis of cytochrome $c$ (Figure 4a). In cells exposed to staurosporine for $1 \mathrm{~h}$, translocation of cytochrome $c$ from mitochondria to the cytosol was observed (Figure 4b). In cells pretreated with pepstatin $A$, almost no release of cytochrome $c$ was detected after up to $6 \mathrm{~h}$
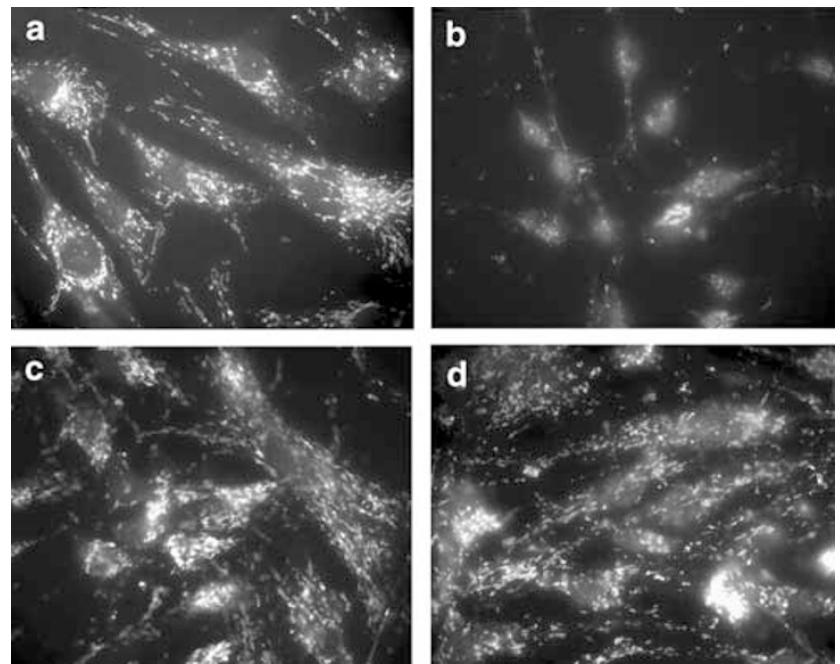

Figure 4 Inhibition of cathepsin D prevents mitochondrial release of cytochrome $c$. Immunofluorescence detection of cytochrome $c$ in human foreskin fibroblasts. (a) Control cells. (b) Cells exposed to $0.1 \mu \mathrm{M}$ staurosporine for $1 \mathrm{~h}$. (c) Cells pretreated with pepstatin $A(100 \mu \mathrm{M}, 24 \mathrm{~h})$ and then exposed to staurosporine for $1 \mathrm{~h}$. (d) Cells pretreated with pepstatin $A$ and then exposed to staurosporine for $6 \mathrm{~h}$ 
of exposure to staurosporine (Figures 4c, d). Treatment of cells with pepstatin $A$ alone did not affect cytochrome $c$ distribution (data not shown). These results indicate that cathepsin D activity contributes to mitochondrial cytochrome $c$ release in staurosporine-treated fibroblasts.

\section{Inhibition of cathepsin D activity prevents activation of caspase- 9 and -3}

In order to investigate if cathepsin D plays a role in the activation of caspases during staurosporine-induced apoptosis, the activity of caspase- 9 and -3 was analysed with and without pepstatin A pretreatment. Figures $5 \mathrm{a}$ and $\mathrm{b}$ demonstrate that caspase- 9 and -3 activity increased with time of exposure to staurosporine. Activation of caspase-9 and -3 was confirmed by Western blot analysis using antibodies raised towards the p17 and p37 cleavage fragments of caspase- 9 and -3 , respectively (Figures $5 c, d$ ). As seen in Figures $5 a$ and $b$, the increase in activity was largely prevented by inhibition of cathepsin D activity. Pepstatin A was previously found to have no direct effect on recombinant caspase-3 activity. ${ }^{4}$

Pretreatment of cells with Ac-DEVD-CHO, an inhibitor of caspase-3-like caspases, did not completely prevent apoptosis, but offered protection similar to that afforded by pepstatin $A$, resulting in delayed cell death (data not shown). This section of the work demonstrates that inhibition of cathepsin D activity prevents caspase activation, which results in delayed cell death.

\section{Caspase-8 activity and cleavage of Bid}

As it has been demonstrated that caspase-8 could be involved in lysosomal destabilisation, ${ }^{2}$ we also investigated the time course of caspase- 8 activation and the effect of a caspase- 8
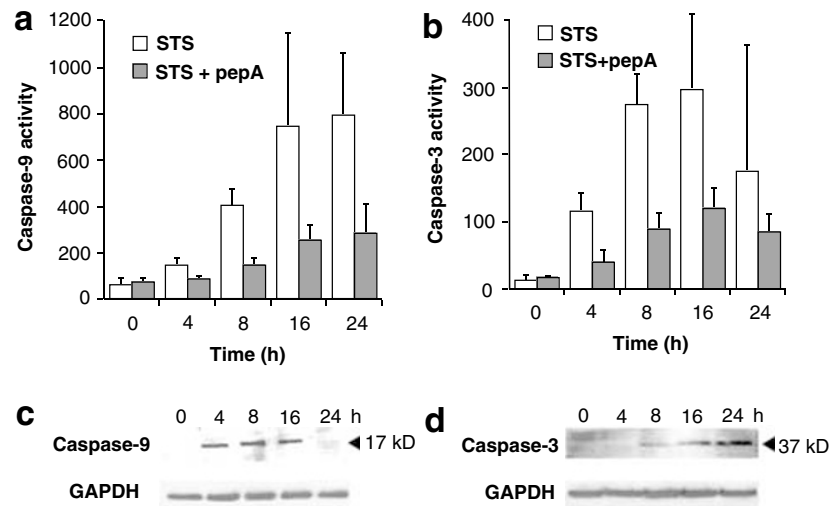

Figure 5 Inhibition of cathepsin D prevents activation of caspase- 9 and -3 in human foreskin fibroblasts. (a) Caspase- 9 activity (arbitrary units/ $\mu \mathrm{g}$ protein $/ \mathrm{h}$ ). (b) Caspase-3 activity (pmol AMC/mg protein/h). Cells were exposed to $0.1 \mu \mathrm{M}$ staurosporine (STS) for different periods of time. Where indicated, cells were treated with $100 \mu \mathrm{M}$ pepstatin $\mathrm{A}$ (pep A) for $24 \mathrm{~h}$ before staurosporine exposure. The activity of caspase- 9 (at 4, 8,16 and $24 \mathrm{~h}$ ) and caspase-3 (at 4, 8 and $16 \mathrm{~h}$ ) was significantly reduced in cells pretreated with pepstatin $A$ as compared to pepstatin A-untreated cells $(P<0.05)$. Means \pm S.D. are shown, $n=4-6$. (c) Western blot analysis of cleaved caspase- 9 and (d) cleaved caspase- 3 in cells exposed to staurosporine for indicated periods of time. GAPDH was used as loading control a

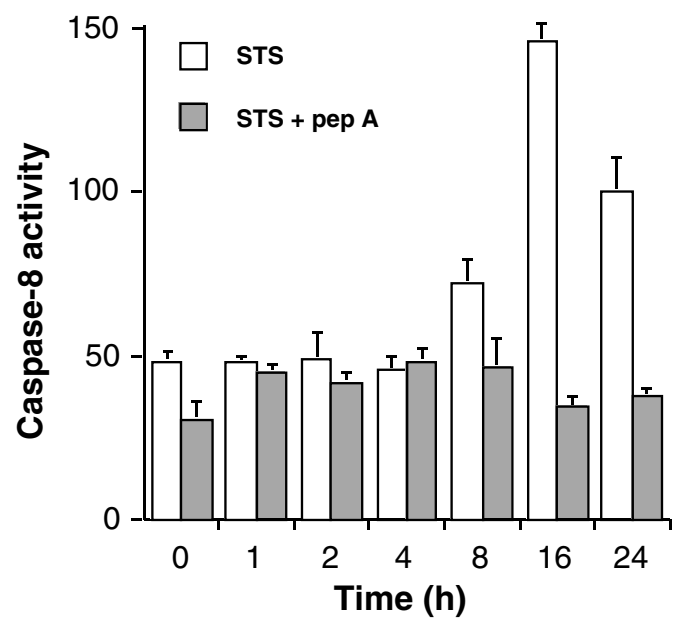

b
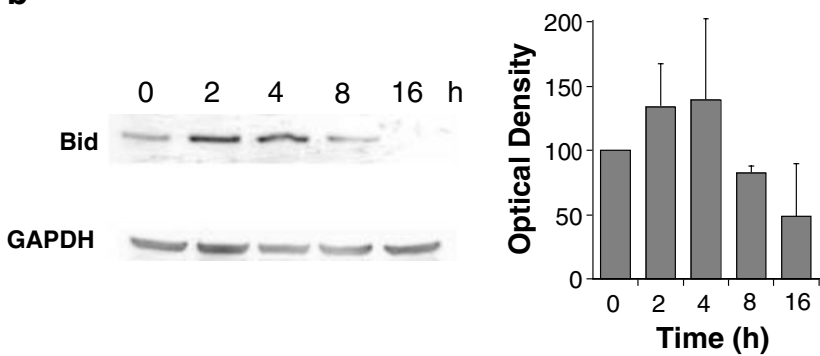

Figure 6 Caspase-8 activation and cleavage of Bid (a) Caspase-8 activity (arbitrary units/ $\mu \mathrm{g}$ protein/h). Cells were exposed to $0.1 \mu \mathrm{M}$ staurosporine (STS) for different periods of time. Where indicated, cells were treated with $100 \mu \mathrm{M}$ pepstatin A (pep A) for $24 \mathrm{~h}$ before staurosporine exposure. In staurosporinetreated cells, there was a significant increase in caspase-8 activity at 8,16 and $24 \mathrm{~h}$ as compared to the untreated control. Caspase-8 activity was significantly reduced in cells pretreated with pepstatin $A$ as compared to pepstatin $A$ untreated cells at these time points. Means \pm S.D. are shown, $n=4$. (b) Western blot analysis of full-length Bid from fibroblasts exposed to $0.1 \mu \mathrm{M}$ staurosporine for indicated periods of time. One representative blot out of four is presented. GAPDH was used as loading control. The diagram shows means \pm S.D. from densitometry analysis of all four blots. There is a statistically significant decrease in full-length Bid after 8 and $16 \mathrm{~h}$ of exposure as compared to the control, indicating cleavage of Bid

inhibitor on cell death. Caspase-8 activity was detected after $8 \mathrm{~h}$ of staurosporine treatment, but was absent in pepstatin $\mathrm{A}$ pretreated cells (Figure 6a). Moreover, the caspase-8 inhibitor Ac-IETD-CHO offered no protection from staurosporineinduced death (data not shown). These results, showing activation of caspase- 8 several hours after the release of cathepsin D from lysosomes, indicate that caspase- 8 is not responsible for the early lysosomal destabilisation. In this experimental system, caspase- 8 rather seems to be activated at a later stage in the caspase cascade.

Stoka et al. ${ }^{10}$ have shown that Bid can be cleaved and activated by lysosomal extracts. Therefore, we investigated whether Bid could be a downstream target of cathepsin D proteolytic activity. Cleavage of Bid, detected as a decrease in the full-length protein, was detected after $8 \mathrm{~h}$ of staurosporine exposure (Figure $6 \mathrm{~b}$ ). The lack of an early activation of Bid suggests that this bcl-2 family member is not a mediator of cathepsin D-dependent mitochondrial release of cytochrome $c$. 


\section{Discussion}

In the present study, lysosomal release of cathepsin D to the cytosol was detected after $1 \mathrm{~h}$ of exposure to staurosporine. A similar translocation of cathepsins $B, D$ and $L$ was previously observed during oxidative stress-induced apoptosis, ${ }^{4}$ and of cathepsin B in TNF- $\alpha$-induced apoptosis. ${ }^{2,3}$ The mechanism by which lysosomal proteases are released to the cytosol is still unknown, but there are several possibilities. Atractyloside, which opens the mitochondrial permeability transition pore, has been shown to also cause release of cathepsin B into the cytosol, suggesting the possible existence of similar pores in the lysosomal membrane. ${ }^{22}$ Lysosomal proteases may also be released by a nonselective mechanism, such as increased permeability of the lysosomal membrane, which under specific circumstances, may be due to oxidative damage. ${ }^{14}$ In the present study, antioxidant treatment did not protect cells from staurosporine-induced death. This implies a release mechanism independent of oxidative events. Guicciardi et $a l^{2}$ have presented evidence that caspase- 8 is involved in the destabilisation of lysosomes. This appears, however, not to be the case in our experimental system, since activation of caspase- 8 was not detected until several hours after the release of cathepsin $D$ from lysosomes. Yet another mechanism has been presented by Zhao et al., ${ }^{23}$ who suggest that activation of phospholipase A2 is involved in destabilisation of lysosomes during apoptosis. Thus, elucidation of the mechanism(s) resulting in the lysosomal release of cathepsin $D$ during apoptosis clearly requires further investigation.

Inhibition of cathepsin D activity prevented cytochrome $c$ release, caspase- 9 and -3 activation and delayed cell death induced by staurosporine. Even a $1 \mathrm{~h}$ exposure to staurosporine caused massive cell death over the subsequent $24 \mathrm{~h}$, indicating that the decisive apoptotic events occur quite early. Moreover, after $1 \mathrm{~h}$ of staurosporine exposure cathepsin D was already translocated from the lysosomes to the cytosol. As inhibition of the cathepsin D activity rescues cells otherwise destined to die, this release may be a critical step, allowing cathepsin D to interact with its downstream targets. This is supported by a recent report from our group, in which apoptosis was induced by microinjection of cathepsin $D$ into the cytosol. ${ }^{16}$ Cathepsin D probably acts upstream of mitochondrial events, activating proapoptotic or inactivating antiapoptotic factors, which ultimately results in the release of cytochrome $c$. The decreased caspase activation observed in the presence of pepstatin $A$ is probably due to the inhibition of cathepsin Dmediated cytochrome $c$ release. In our search for possible targets of cathepsin D, we studied Bid cleavage in our experimental model. Stoka et al. ${ }^{10}$ have, in an in vitro system combining recombinant mouse Bid and lysosomal extracts, demonstrated cleavage and activation of Bid by lysosomal proteases. These studies indicated that Bid cleavage was a major link between lysosomal proteases and cytochrome $c$ release. In the present study, Bid cleavage was not initiated until after $8 \mathrm{~h}$ of staurosporine exposure, while translocation of cathepsin $D$ from lysosomes and cytochrome $c$ from mitochondria was detected after only $1 \mathrm{~h}$. These findings suggest that the release of cytochrome $c$, in our system, is independent of Bid cleavage. There is a possibility, though, that a low level of Bid cleavage (below detection limits) is enough to propagate the apoptotic signal. It appears, however, that cathepsin $D$ has other targets in fibroblasts.

Since other lysosomal proteases, for example, cathepsin B, have been found to be mediators of apoptosis in other experimental systems, one may speculate that the release of lysosomal proteases in general will lead to the induction of apoptosis. The importance of different lysosomal proteases in mediating apoptosis may then vary with cell type (depending on the relative abundance of each protease). In human foreskin fibroblasts, however, cathepsin D clearly plays a dominant role as inhibition of cysteine proteases like cathepsins $B$ and $L$ did not have any effect on staurosporine-induced apoptosis. Moreover, inhibition of cathepsin B activity with CA-074 Me does not inhibit oxidative stressinduced apoptosis, ${ }^{4}$ and microinjection of cathepsin B into the cytosol of these cells does not induce apoptosis. ${ }^{16}$

Earlier studies have shown that staurosporine-induced apoptosis can also occur via an alternative, caspaseindependent, pathway. ${ }^{24,25}$ Belmokhtar et al. ${ }^{25}$ demonstrated that, when pretreating L1210 cells with Z-VAD-fmk, a broadspectrum caspase inhibitor, staurosporine-induced apoptosis was delayed but not prevented. In the present study, similar results were obtained when human fibroblasts were treated with an inhibitor of caspase-3-like caspases. These data suggest that staurosporine can induce apoptosis through at least two parallel pathways; one that is caspase-dependent, and another that is independent of caspases and results in delayed cell death. Inhibition of cathepsin D activity prevents caspase activation and delays apoptosis. Moreover, in apoptotic fibroblasts pretreated with pepstatin A prior to staurosporine exposure, the nucleus was not as condensed and fragmented as in cells exposed to staurosporine only. Lack of caspase-3 activation is probably the explanation for these results, since caspase-3 is required for DNA fragmentation and some of the other typical morphological changes in cells undergoing apoptosis. ${ }^{26} \mathrm{We}$ therefore suggest that cathepsin $D$ is essential for the activation of caspases via the mitochondrial pathway, and, consequently, induction of early cell death during exposure of fibroblasts to staurosporine.

In this study, we demonstrate that translocation of cathepsin D from lysosomes to the cytosol is an early event in staurosporine-induced apoptosis. Inhibition of cathepsin D activity prior to staurosporine exposure resulted in suppressed mitochondrial release of cytochrome $c$, reduced caspase activation, and delayed cell death. Taken together, these results implicate cathepsin $D$ as a key component in human fibroblast apoptosis induced by staurosporine.

\section{Materials and Methods}

\section{Cells and culture conditions}

Human foreskin fibroblasts, AG-1518 (passages 14-20; Coriell Institute, Camden, NJ, USA), were cultured in Eagle's minimum essential medium supplemented with $2 \mathrm{mM}$ glutamine, $50 \mathrm{IU} / \mathrm{ml}$ penicillin-G, $50 \mu \mathrm{g} / \mathrm{ml}$ streptomycin, and $10 \%$ foetal bovine serum (all from GIBCO, Paisly, 
UK). Cells were incubated in humidified air with $5 \% \mathrm{CO}_{2}$ at $37^{\circ} \mathrm{C}$, and were subcultured once a week. At $48 \mathrm{~h}$ prior to the experiments, cells were trypsinised and seeded into $35-\mathrm{mm}$ Petri dishes (Costar, Cambridge, MA, USA) at a density of $10000 \mathrm{cells} / \mathrm{cm}^{2}$. For light microscopic analyses, cells were grown on round glass coverslips (diameter $22 \mathrm{~mm})$. Staurosporine $(0.1 \mu \mathrm{M}$; stock solution, $0.2 \mathrm{mM}$ in dimethyl sulphoxide; Sigma, St. Louis, MO, USA) was added to the cultures in a prewarmed $\left(37^{\circ} \mathrm{C}\right)$ serum-free medium, and cells were incubated at $37^{\circ} \mathrm{C}$ for up to $24 \mathrm{~h}$, or for $60 \mathrm{~min}$ and then back to complete culture medium with serum for $24 \mathrm{~h}$, before analysis. Some cultures were treated with pepstatin A $(100 \mu \mathrm{M}$; stock solution, $25 \mathrm{mM}$ in dimethyl sulphoxide; Sigma) $24 \mathrm{~h}$ before, during and after staurosporine exposure. Others were treated with the antioxidant DPPD $(2 \mu \mathrm{M}$; stock solution, $1 \mathrm{mM}$ in dimethyl sulphoxide; Aldrich chemical company, Milwaukee, USA), the cysteine protease inhibitor z-FA-FMK ( $100 \mu \mathrm{M}$; $2 \mathrm{~h}$ preincubation; stock solution, $10 \mathrm{mM}$ in dimethyl sulphoxide; Enzyme Systems Products, Livermore, CA, USA) or the caspase inhibitors Ac-DEVD-CHO $(50 \mu \mathrm{M}$; $1 \mathrm{~h}$ preincubation; stock solution, $2 \mathrm{mM}$ in dimethyl sulphoxide; Calbiochem, San Diego, CA, USA) and Ac-IETD$\mathrm{CHO}(50 \mu \mathrm{M} ; 2 \mathrm{~h}$ preincubation; stock solution, $2 \mathrm{mM}$ in dimethyl sulphoxide; Calbiochem).

\section{Examination of cell morphology}

Cell morphology was examined by light microscopy following fixation in 4\% phosphate-buffered formaldehyde and staining with a $5 \%$ Giemsa solution (Merck, Darmstadt, Germany), or by electron transmission microscopy as described earlier. ${ }^{27}$ Briefly, cells were fixed in situ in the plastic culture dish by addition of $2 \%$ glutaraldehyde (Agar Scientific, Essex, UK) in $0.1 \mathrm{M}$ sucrose/sodium-cacodylate-HCl buffer (Sigma), pH 7.2, and postfixed in osmium tetraoxide (Johnson Matthey Chemicals, Roystone, UK). Dehydration, staining en bloc with uranyl acetate, dehydration and embedding in Epon-812 (Fluka AG, Buchs, Switzerland) were also performed in the culture dish. Thin sections of the cured block were cut with a diamond knife (DIATOME, Bienne, Switzerland), stained with leadcitrate, examined, and photographed in a JEOL 1200-EX electron microscope (Tokyo, Japan) at $100 \mathrm{kV}$.

\section{Immunofluorescence detection of cathepsin D and cytochrome $c$}

Fibroblasts grown on coverslips were fixed in $4 \%$ paraformaldehyde (Fluka AG) in phosphate-buffered saline (PBS) for $20 \mathrm{~min}$ at $4^{\circ} \mathrm{C}$, and prepared for immunocytochemistry as described earlier. ${ }^{27}$ Briefly, cells were incubated with a polyclonal rabbit anti-human cathepsin $D$ antibody (dilution 1:100; Dako, Glostrup, Denmark) followed by a Texas Redconjugated goat anti-rabbit IgG antibody (dilution 1:200; Vector Laboratories, Burlingame, CA, USA), or a monoclonal mouse anti-human cytochrome $c$ antibody (dilution 1: 50; Pharmingen, San Diego, CA, USA) followed by an FITC-conjugated rabbit anti-mouse IgG antibody (dilution 1:50; Calbiochem). Finally, cells were rinsed in PBS and distilled water, and mounted in Vectashield Mounting Medium (Vector Laboratories). Examination was performed using a Nikon photomicroscope (Nikon Corporation, Tokyo, Japan) with green exciting light and a red barrier filter for cathepsin D, and with blue exciting light and a green barrier filter for cytochrome $c$. Images were captured with a digital video camera (Hamamatsu, Tokyo, Japan). Controls incubated without anti-cathepsin D or anti-cytochrome $c$ antibodies did not stain.

\section{Extraction of cytosol}

Release of cathepsin D from lysosomes to the cytosol was detected by Western blot analysis of cytosol extracted by using digitonin. Digitonin is a cholesterol-solubilising agent that, in low concentrations, permeabilises cholesterol-rich membranes such as the plasma membrane, but leaves Iysosomal and mitochondrial membranes, which are cholesterol-poor, intact. Cell culture dishes were incubated rocking $(100 \mathrm{rpm})$ on ice for $12 \mathrm{~min}$ in extraction buffer ( $250 \mathrm{mM}$ sucrose, $20 \mathrm{mM}$ Hepes, $10 \mathrm{mM} \mathrm{KCl}$, $1.5 \mathrm{mM} \mathrm{MgCl} 2,1 \mathrm{mM}$ EDTA and $1 \mathrm{mM}$ EGTA) containing $25 \mu \mathrm{g} / \mathrm{ml}$ digitonin. The digitonin concentration and the exposure time were optimised to result in maximum release of cytosolic lactate dehydrogenase (activity analysed as described by Vassault ${ }^{28}$ ) without disruption of lysosomes. The extraction buffer was withdrawn and proteins were precipitated by addition of $5 \%$ trichloric acid. After a 10 min incubation on ice, proteins were pelleted by centrifugation $(20800 \times \mathrm{g}, 15 \mathrm{~min})$. The pellet was dissolved in lysis buffer (see Western blot protocol below) containing $6 \mathrm{M}$ urea, and the sample was neutralised by addition of $4 \mu \mathrm{l}$ $1 \mathrm{M} \mathrm{NaOH} / 100 \mu \mathrm{l}$ sample. PAGE and blotting was performed as described below.

\section{Measurement of caspase activity}

Caspase-3 activity was measured using the fluorescent substrate AcDEVD-7-amino-4-methyl coumarin (Ac-DEVD-AMC; Becton-Dickinson, Mountain View, CA, USA), which is cleaved by caspases with caspase-3like specificity. Measurements were performed according to the manufacturer's instructions. After incubation for $1 \mathrm{~h}$ at $37^{\circ} \mathrm{C}$, the amount of released AMC was analysed at $\lambda_{\text {ex }} 380 \mathrm{~nm}$ and $\lambda_{\text {em }} 435 \mathrm{~nm}$ in an RF540 Spectrofluorophotometer (Shimadzu, Kyoto, Japan). The amount of released $A M C$ was calculated using a standard curve, and correlated to total protein determined by the method described by Lowry et al..$^{29}$ Caspase-3 activity was expressed in pmol AMC/mg protein/h.

Caspase- 9 activity was measured using a Caspase- 9 fluorometric kit (R\&D Systems, Minneapolis, MN, USA) according to the manufacturer's instructions. After incubation for $1 \mathrm{~h}$ and $45 \mathrm{~min}$ at $37^{\circ} \mathrm{C}$, release of fluorescent 7-amino-4-trifluoromethyl coumarin (AFC) from the caspase-9specific substrate Ac-LEHD-AFC was analysed at $\lambda_{\mathrm{ex}} 380 \mathrm{~nm}$ and $\lambda_{\mathrm{em}}$ $500 \mathrm{~nm}$ in a Victor plate reader (EG\&G Wallac, Upplands Väsby, Sweden). Caspase- 9 activity is expressed in arbitrary units/ $\mu \mathrm{g}$ protein $/ \mathrm{h}$.

Caspase-8 activity was measured using the fluorescent substrate AcIETD-AFC (Becton-Dickinson), which is cleaved by activated caspase-8. Cells were lysed in $50 \mu \mathrm{l} 10 \mathrm{mM}$ Tris- $\mathrm{HCl}$ buffer containing $10 \mathrm{mM}$ $\mathrm{NaH}_{2} \mathrm{PO}_{4} / \mathrm{Na}_{2} \mathrm{HPO}_{4}(\mathrm{pH} 7.4), 130 \mathrm{mM} \mathrm{NaCl}, 1 \%$ Triton X-100 and $10 \mathrm{mM}$ sodium pyrophosphate. The lysate was mixed with $245 \mu \mathrm{l} 20 \mathrm{mM}$ PIPES buffer (pH 7.2) containing $100 \mathrm{mM} \mathrm{NaCl}, 10 \mathrm{mM}$ dithiotreitol, $1 \mathrm{mM}$ EDTA, $0.1 \%$ CHAPS and $10 \%$ sucrose. Substrate $(23 \mu \mathrm{M})$ was added, and after $1 \mathrm{~h}$ of incubation at $37^{\circ} \mathrm{C}$ fluorescence released AFC was analysed in a Victor plate reader at $\lambda_{\mathrm{ex}} 380 \mathrm{~nm}$ and $\lambda_{\mathrm{em}} 500 \mathrm{~nm}$. Caspase- 8 activity is expressed in arbitrary units/ $\mu \mathrm{g}$ protein $/ \mathrm{h}$.

\section{Western blot}

Cells were washed in PBS and lysed in $63 \mathrm{mM}$ Tris-HCl buffer ( $\mathrm{pH} \mathrm{6.8)}$ containing $10 \%$ glycerol, $2 \%$ SDS, 5\% 2-mercaptoethanol and $0.05 \%$ bromphenol blue. The protein concentration was determined, ${ }^{29}$ and $100 \mu \mathrm{g}$ aliquots were analysed by $12 \%$ (cathepsin D), $15 \%$ (Bid) or $4-20 \%$ (caspase-3 and -9) SDS-PAGE. Proteins were transferred onto a nitrocellulose membrane, which was subsequently blocked for $90 \mathrm{~min}$ at room temperature in Tris-buffered saline (TBS; $50 \mathrm{mM}$ Tris and $0.15 \mathrm{M}$ 
$\mathrm{NaCl}, \mathrm{pH} 7.5)$ containing $5 \%$ skimmed milk and $0.1 \%$ Tween-20. After washing in TBS, the membrane was incubated at $4^{\circ} \mathrm{C}$ overnight with a mouse anti-cathepsin D antibody (dilution 1:1000; Oncogene Research Products, San Diego, CA, USA), a rabbit anti-Bid antibody (dilution 1:1000; Cell Signaling Technology, Beverly, MA, USA), a rabbit anticaspase-9 (cleaved) antibody (dilution 1:200; Oncogene Research Products) or a rabbit anti-caspase-3 (cleaved) antibody (dilution 1:200; Oncogene Research Products) diluted in TBS containing $0.1 \%$ skimmed milk and $0.05 \%$ Tween-20. The membrane was washed and incubated for $1 \mathrm{~h}$ at room temperature with a peroxidase-conjugated anti-mouse or antirabbit antibody (dilution 1: 1500; Dako), and the bands were visualised by ECL plus (Amersham Pharmacia Biotech, Buckinghamshire, England). Equal loading was verified by reprobing the membrane with a mouse antiglyceraldehyde-3-phosphate dehydrogenase (GAPDH) antibody (dilution $1: 2000$; Biogenesis, Poole, UK) followed by a goat anti-mouse antibody (dilution 1:1500; Dako). Densitometry was performed using Fujifilm Image Gauge Ver. 3.0 software.

\section{Statistical analysis}

Experiments were repeated three to six times, and statistical significance was determined using the Kruskal-Wallis multiple comparison test. Differences were considered significant when $P \leq 0.05$.

\section{Acknowledgements}

This work was financially supported by the Swedish Cancer Foundation (Grant No. 2703), the Swedish Research Council (Grant No. 14259) and Östergötlands läns landsting. We thank Dr. Katarina Kägedal and Dr. Uno Johansson for fruitful discussions and Dr. Brett Garner for linguistic help.

\section{References}

1. Cohen GM (1997) Caspases: the executioners of apoptosis. Biochem. J. 326: $1-16$

2. Guicciardi ME, Deussing J, Miyoshi H, Bronk SF, Svingen PA, Peters C, Kaufmann SH and Gores GJ (2000) Cathepsin B contributes to TNF- $\alpha$ mediated hepatocyte apoptosis by promoting mitochondrial release of cytochrome c. J. Clin. Invest. 106: 1127-1137

3. Foghsgaard L, Wissing D, Mauch D, Lademann U, Bastholm L, Boes M, Elling F, Leist M and Jäättelä M (2001) Cathepsin B acts as a dominant execution protease in tumor cell apoptosis induced by tumor necrosis factor. J. Cell Biol. 153: 999-1009

4. Kägedal K, Johansson $U$ and Öllinger K (2001) The lysosomal protease cathepsin $D$ mediates apoptosis induced by oxidative stress. FASEB J. 15: 1592-1594

5. Öllinger K (2000) Inhibition of cathepsin D prevents free-radical-induced apoptosis in rat cardiomyocytes. Arch. Biochem. Biophys. 373: 346-351

6. Roberg K, Johansson U and Öllinger K (1999) Lysosomal release of cathepsin $D$ precedes relocation of cytochrome $c$ and loss of mitochondrial transmembrane potential during apoptosis induced by oxidative stress. Free Radic. Biol. Med. 27: 1228-1237

7. Katunuma N, Matsui A, Le QT, Utsumi K, Salvesen G and Ohashi A (2001) Novel procaspase-3 activating cascade mediated by lysoapoptases and its biological significances in apoptosis. Adv. Enzyme Regul. 41: 237-250

8. Ishisaka R, Utsumi T, Yabuki M, Kanno T, Furuno T, Inoue M and Utsumi K (1998) Activation of caspase-3-like protease by digitonin-treated lysosomes. FEBS Lett. 435: 233-236
9. Ishisaka R, Utsumi T, Kanno T, Arita K, Katunuma N, Akiyama J and Utsumi K (1999) Participation of a cathepsin-L-type protease in the activation of caspase3. Cell Struct. Funct. 24: $465-470$

10. Stoka V, Turk B, Schendel SL, Kim T-H, Cirman T, Snipas SJ, Ellerby LM, Bredesen D, Freeze H, Abrahamson M, Börmme D, Krajewski S, Reed JC, Yin X-M, Turk V and Salvesen GS (2000) Lysosomal protease pathway to apoptosis: cleavage of Bid, not pro-caspases, is the most likely route. J. Biol. Chem. 276: 3149-3157

11. Shibata M, Kanamori S, Isahara K, Ohsawa Y, Konishi A, Kametaka S, Watanabe T, Ebisu S, Ishido K, Kominami E and Uchiyama Y (1998) Participation of Cathepsins $B$ and $D$ in apoptosis of $P C 12$ cells following serum deprivation. Biochem. Biophys. Res. Commun. 251: 199-203

12. Isahara K, Ohsawa $Y$, Kanamori S, Shibata M, Waguri S, Sato N, Gotow T, Watanabe T, Momoi T, Urase K, Kominami E and Uchiyama Y (1999) Regulation of a novel pathway for cell death by lysosomal aspartic and cysteine proteinases. Neuroscience 91: 233-249

13. Deiss LP, Galinka H, Berissi H, Cohen O and Kimchi A (1996) Cathepsin D protease mediates programmed cell death induced by interferon- $\gamma$, Fas/APO-1 and TNF- $\alpha$. EMBO J. 15: 3861-3870

14. Roberg K and Öllinger K (1998) Oxidative stress causes relocation of the Iysosomal enzyme cathepsin $D$ with ensuing apoptosis in neonatal rat cardiomyocytes. Am. J. Pathol. 152: 1151-1156

15. Roberg K (2001) Relocalization of cathepsin D and cytochrome $c$ early in apoptosis revealed by immunoelectron microscopy. Lab. Invest. 81: 149-158

16. Roberg K, Kägedal K and Öllinger K (2002) Microinjection of cathepsin D induces caspase-dependent apoptosis in fibroblasts. Am. J. Pathol. 161: 89-96

17. Shields PP, Gonzales TA, Charles D, Gilligan JP and Stern W (1991) Accumulation of pepstatin in cultured endothelial cells and its effect on endothelial processing. Biochem. Biophys. Res. Commun. 177: 1006-1012

18. Öllinger K and Brunk UT (1995) Cellular injury induced by oxidative stress is mediated through lysosomal damage. Free Radic. Biol. Med. 19: 565-574

19. Heiskanen KM, Bhat MB, Wang H-W, Ma J and Nieminen A-L (1999) Mitochondrial depolarization accompanies cytochrome $c$ release during apoptosis in PC6 cells. J. Biol. Chem. 274: 5654-5658

20. Tafani M, Minchenko DA, Serroni A and Farber JL (2001) Induction of the mitochondrial permeability transition mediates the killing of HeLa cells by staurosporine. Cancer Res. 61: 2459-2466

21. Stepczynska A, Lauber K, Engels IH, Janssen O, Kabelitz D, Wesselborg S and Schulze-Osthoff K (2001) Staurosporine and conventional anticancer drugs induce overlapping, yet distinct pathways of apoptosis and caspase activation. Oncogene 20: 1193-1202

22. Vancompernolle K, Van Herreweghe F, Pynaert G, Van de Craen M, De Vos K, Totty N, Sterling A, Fiers W, Vandenabeele P and Grooten J (1998) Atractyloside-induced release of cathepsin B, a protease with caspaseprocessing activity. FEBS Lett. 438: 150-158

23. Zhao M, Brunk UT and Eaton JW (2001) Delayed oxidant-induced cell death involves activation of phospholipase A2. FEBS Lett. 509: 399-404

24. Andersson M, Sjostrand J, Petersen A, Honarvar AK and Karlsson JO (2000) Caspase and proteasome activity during staurosporine-induced apoptosis in lens epithelial cells. Invest. Ophthalmol. Vis. Sci. 41: 2623-2632

25. Belmokhtar CA, Hillion $J$ and Segal-Bendirdjian E (2001) Staurosporine induces apoptosis through both caspase-dependent and caspase-independent mechanisms. Oncogene 20: 3354-3362

26. Jänicke RU, Sprengart ML, Wati MR and Porter AG (1998) Caspase-3 is required for DNA fragmentation and morphological changes associated with apoptosis. J. Biol. Chem. 273: 9357-9360

27. Brunk UT, Zhang H, Roberg K and Öllinger K (1995) Lethal hydrogen peroxide toxicity involves lysosomal iron-catalyzed reactions with membrane damage. Redox Rep. 1: 267-277

28. Vassault A. (1985) Lactate dehydrogenase. UV method with pyruvate and $\mathrm{NADH}$. In Methods of Enzymatic Analysis, Vol. 3, Bergemeyer H, ed (London: Academic Press), pp. 118-126

29. Lowry OH, Rosebrough NJ, Farr AL and Randall RJ (1951) Protein measurement with the folin phenol reagent. J. Biol. Chem. 193: 265-275 